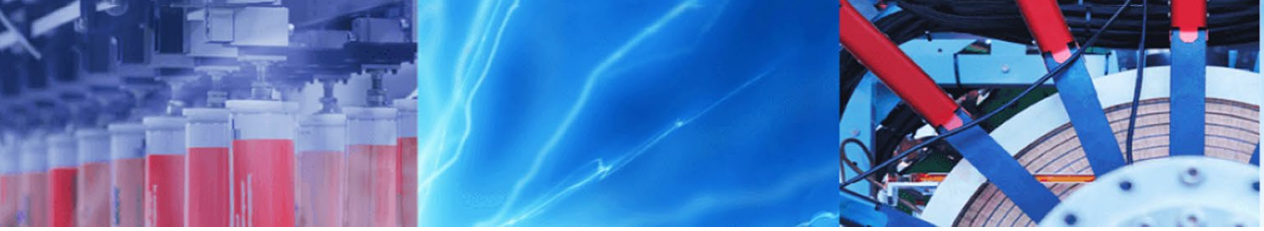

Research Article

\title{
Modelling approach for analysis of moisture transport in diatomaceous earth pellets
}

\author{
Carlos I. Cortés-Martínez ${ }^{1}$ (D) . Sadoth Sandoval-Torres ${ }^{2}$ (D) . Jaime Ruiz-Vega ${ }^{3}$ (D) - Pastor T. Matadamas-Ortiz ${ }^{2}$. \\ Teodulfo Aquino-Bolaños ${ }^{3}$ (i)
}

Received: 26 January 2020 / Accepted: 29 August 2020 / Published online: 12 September 2020

(c) Springer Nature Switzerland AG 2020

\begin{abstract}
Gradual moisture loss from spherical porous pellets is a prerequisite to induce entomopathogenic nematodes into a partial state of anhydrobiosis and for extending their shelf-life under non-controlled storage conditions. The aim of this work was to analyse the moisture loss in diatomaceous earth pellets through a mathematical model based on the molecular diffusion into a spherical porous structure. A natural and a forced convection scenarios were studied. For the experiments, pellets of $5 \mathrm{~mm}$ in radius with an initial moisture content of $1.0\left(\mathrm{~kg} \mathrm{H}_{2} \mathrm{O} / \mathrm{kg}\right.$ dry matter) were stored at $23^{\circ} \mathrm{C}$ and $96 \%$ relative humidity. The moisture loss represents a drying process in two-stages and a crack formation in the pellet was observed, causing a moisture re-absorption phenomenon between 5 and 8 days; this event could originate an increase of the macro-porosity and the capillary pressure. The theoretical prediction showed a better accuracy for natural convection. The deviation in the case of forced convection is explained by the crack formation, which was not considered in the model.
\end{abstract}

Keywords Modelling · Porous pellet · Convection · Biopesticide · Entomopathogenic nematode

\section{Introduction}

The distribution of moisture content $(\mathrm{MC})$ and the drying rate are important criteria in the design of porous pellets for biological applications [1-4]. Through the formulation process, the infective juvenile (IJ) stage of entomopathogenic nematodes (EPNs) is conditioning as a product to exploit their pathogenicity for the biological control of insect pests in agricultural crops $[1,5,6]$. Anhydrobiosis is a temporary state of arrested metabolism of the IJs that is reached under a low rate of moisture loss in soils, which is reversible as soon as a better moisture condition is restored [7]. The storage stability of the EPNs in granular formulations has been improved by taking advantage of this nematode survival strategy [8], since the viability and effectivity needs to be guaranteed without refrigeration for up to 18 months, as a fundamental product requirement specification for achieve the user acceptance and commercialization of EPN biopesticide $[1,9,10]$.

The desiccation process to ensure the shelf life of formulated IJs has been extrinsically controlled by proper selection of carrier materials, adjuvants, the manufacturing method and the control of storage conditions $[1,6$, 11]. S. carpocapsae IJs have been formulated into waterdispersible granules (WDGs) [12]. During the storage period, there was a decrease in oxygen consumption and use of lipids associated with an increase in survival time, which reached seven months under storage conditions at $25^{\circ} \mathrm{C}$, demonstrating that the induction to anhydrobiosis in granular formulations increases the longevity of the IJs

Carlos I. Cortés-Martínez, solemia7@hotmail.com | ${ }^{1}$ Cuerpo Académico de Biotecnología Agroalimentaria, Instituto de Ciencias Agropecuarias, Universidad Autónoma del Estado de Hidalgo, 43600 Tulancingo de Bravo, Hidalgo, México. ${ }^{2}$ Instituto Politécnico Nacional, CIIDIR Oaxaca, Ingeniería, 71230 Santa Cruz Xoxocotlán, Oaxaca, México. ${ }^{3}$ Instituto Politécnico Nacional, CIIDIR Oaxaca, Protección y Producción Vegetal, 71230 Santa Cruz Xoxocotlán, Oaxaca, México. 
[13]. In contrast, S. glaseri IJs formulated in diatomaceous earth (DE) pellets stored at room temperature (about $23 \pm 2^{\circ} \mathrm{C}$ ) have a short-term storage of 35 days [14].

To better understand and control the drying process of this formulation, it is necessary to formulate mathematical models which can be able to predict the moisture migration patterns. The computational simulation as a tool to predict the transport of moisture in porous media for EPN formulation in pellets is motivated by his usefulness to solve problems analytically so as not to perform unnecessary or expensive experiments on the system and optimize the formulated for specific conditions of storage and application $[15,16]$.

The evolution of MC of the hygroscopic powder materials as $D E$ exposed to the environment depends on their initial $\mathrm{MC}$ and the relative humidity $(\mathrm{RH})$ of the surrounding atmosphere [17]. The drying rate influences the porosity and structure of the resulting dry particles. If particles dried rapidly, the porosity increases strongly from the surface to the interior, so that such particles can be expected to be very porous in the average and even hollow. But, slow drying results in homogeneous and quite compact granule [18].

The spatial changes in $M C$ inside the micro- or mesoporous space are related to the physicochemical properties of its structures, such as volume, shape, and topology of the cavities generated by the particular organisations of the material particles and their movement [19]. The moisture loss from the solid hygroscopicmaterials of the porous structure occur under molecular and capillary transport modes [16]. Molecular diffusion is an essential source of movement at microscopic-scale in the porous structures, where the geometry, size, and sinuosity of the pores determine the mass transfer properties [20], while capillary redistribution causes moisture to migrate within the pore structure such that large pores dry first while small pores remain saturated [21].

Since the gradual reduction of moisture improves the survival of the EPNs in granular formulations, the prediction of moisture loss and the impact on the macroscopic properties of these porous microstructures is crucial for the design of moisture loss control strategies such as material selection (carrier and adjuvants), processing and storage conditions to properly reduce the accelerated moisture loss from pellets containing EPNs. Therefore, this study aimed to analyse the behaviour of the MC of the DE pellets using a mathematical model of moisture transport where the MC gradients are indicators of the driving forces that regulate the rate of moisture loss. The boundary conditions were implemented by considering a forced and a natural convection.

\section{Materials and methods}

\subsection{Materials}

DE (Celite $209^{\mathrm{TM}}$ ) is a filtration material produced by Imerys Minerals California, Inc., which consists of particles originally formed from cell walls of unicellular algae, with radial and bilateral symmetry. The DE particles show different morphologies, from whole cylindrical rods to honeycomb-shaped discs and fragments of rods and discs. Considering the particle size, DE is classified as a powder [22]. For the preparation, DE was dried at $105^{\circ} \mathrm{C}$ for $24 \mathrm{~h}$ in a drying oven. The physical, chemical and thermal properties of this material are shown in Table 1.
Table 1 Physical, chemical and thermal typical properties of diatomaceous earth Celite $209^{\mathrm{TM}}[23-25]$

\begin{tabular}{ll}
\hline Typical properties & Designation and values \\
\hline Physical & BET surface area, $\mathrm{m}^{2} / \mathrm{g}: 10-20$ \\
& Specific gravity: 2.10 \\
& Loose weight, $\mathrm{lb} \mathrm{ft}^{3}: 8 \mathrm{ss}$ \\
& Oil absorption $\%$ by weight: 175 \\
& $\mathrm{pH}: 7$ \\
& Moisture, $\%$ Max: 6 \\
& Refractive index: 143 \\
& Screen analysis: 150 mesh, $0 \% ; 325$ mesh, $0.5 \%$ \\
& d50, Cilas granulometer, Microns: 7 \\
& Density: $220 \mathrm{~kg} / \mathrm{m}^{3} @ @ T$ Total porosity: 0.725 \\
& SiO $2: 86.7, \mathrm{Al}_{2} \mathrm{O}_{3}: 3.3, \mathrm{Fe}_{2} \mathrm{O}_{3}: 1.2, \mathrm{CaO}: 0.5, \mathrm{MgO}: 0.5, \mathrm{Na}_{2} \mathrm{O}+\mathrm{K}_{2} \mathrm{O}: 0.8$, igni- \\
& tion loss: 3.6, others: 2.9 \\
& Calorific capacity: $8.4 \times 10^{-2} \mathrm{~J} / \mathrm{kg} \mathrm{K@@Thermal} \mathrm{conductivity:} 0.05 \mathrm{~W} / \mathrm{m} \mathrm{K}$ \\
Chemical analysis, \% weight &
\end{tabular}




\subsection{Mechanical elaboration of the pellets}

For the elaboration of DE pellets, a pelletizing machine prototype operating on the principle of laminar flow for granulation and a spiral track in spheronization disk under the following operating parameters was used: disk rotation speed of $30 \mathrm{rpm}$, disk inclination angle of $35.7^{\circ}$ and residence time of $5 \mathrm{~s}$ [26]. The pellets have a sphericity coefficient of $87.5 \%$, weighted mean of $0.4 \mathrm{~g}$ and a mean diameter of $10 \mathrm{~mm}$. Twenty pellets were elaborated with $200 \mu$ l droplets of bidistilled water.

\subsection{Storage conditions of the pellets}

Each DE pellet was collected, placed individually in a polypropylene cylindrical container $(44 \mathrm{~mm}$ in diameter and $33 \mathrm{~mm}$ in height) and they were stored into a desiccator (Scienceware brand, Bel-Art Products). The dessicator contained a potassium sulphate saturated solution $\left(\mathrm{K}_{2} \mathrm{SO}_{4}\right)$ to maintain the surrounding atmosphere at $96 \%$ $\mathrm{RH}$ and to minimise the moisture evaporation from DE pellets. The environmental conditions in the desiccator were monitored with a temperature/ $\mathrm{RH}$ data logger $\left(\mathrm{HOBO}^{\circ}\right.$ Pro v2, model U23-001, accuracy of $\pm 0.21^{\circ} \mathrm{C}$ and $\pm 2.5 \% \mathrm{RH}$ ).

\subsection{Determination of the moisture content of the DE pellets}

The weight of each DE pellet was periodically measured by using a digital analytical balance $\left(\mathrm{OHAUS}^{\circ}\right.$, model PA512, accuracy of $\pm 0.02 \mathrm{~g}$ ) until equilibrium. The moisture content of the pellet $\left(M C_{p}\right)$ as a function of the wet and the dry mass was calculated by the following equation:

$M C_{p}=\left[\frac{(\text { wet } \operatorname{mass}(t)-\text { dry mass })}{\text { dry mass }}\right]$

where the wet mass $(t)$ is the weight of the pellet obtained from the daily measurements $(t \geq 0)$ during the experiment. The dry mass is the difference between the initial moist mass of the DE pellet and the mass of the liquid phase, which was $\sim 0.20 \mathrm{~g} \mathrm{(200 \mu l}$ droplet of bidistilled water). The data $M C_{p}$ versus time was fitted by using a nonlinear regression in the mathematical model, and the drying rate, $-\mathrm{dMC}_{\mathrm{p}} / \mathrm{dt}$, was calculated by differentiation in SigmaPlot 12 (Systat Software, Inc., San Jose, CA, USA).

\subsection{Mathematical modelling of moisture transport in the $D E$ pellet}

The system identification method through an iterative process was used in order to build the model $[27,28]$. A conceptual model for the moisture transport in the DE pellet was elaborated, then, the conceptual model was expressed as a mathematical model in the framework of the continuum mechanics. The model allows to compute the evolution of the MC.

\subsubsection{Assumptions}

The pellet was considered as an homogeneous spherical porous medium with constant radius $R$. The system consisted of two phases: a solid non-deformable phase and a liquid phase; the solid phase is hygroscopic, porous and isotropic. The pellet was assumed independent because of in the experiment it was placed individually in a container, which kept them separated from each other. The atmosphere surrounding the pellet was assumed to be at constant temperature and $\mathrm{RH}$.

In the sample, there is no internal heat source since at the beginning the temperature of the pellet is constant and equal to the temperature of the surrounding atmosphere. $A$ one-dimensional transient diffusion was considered, then, the Fick's second law was applied [29]. The medium is anisotropic, and the evaporative process on the surface occurs by convection.

\subsubsection{Equations of moisture transport}

Figure 1 shows a scheme of the pellet and the differential equations for the moisture transfer. The driven force for mass transfer is the difference in moisture concentration between the surface of the pellet and the surrounding air, and it is known as a surface evaporative condition [30]. The differential equation is expressed as:

$-D_{e} \partial M C / \partial R=h_{m}\left(M C_{1}-M C_{0}\right)$

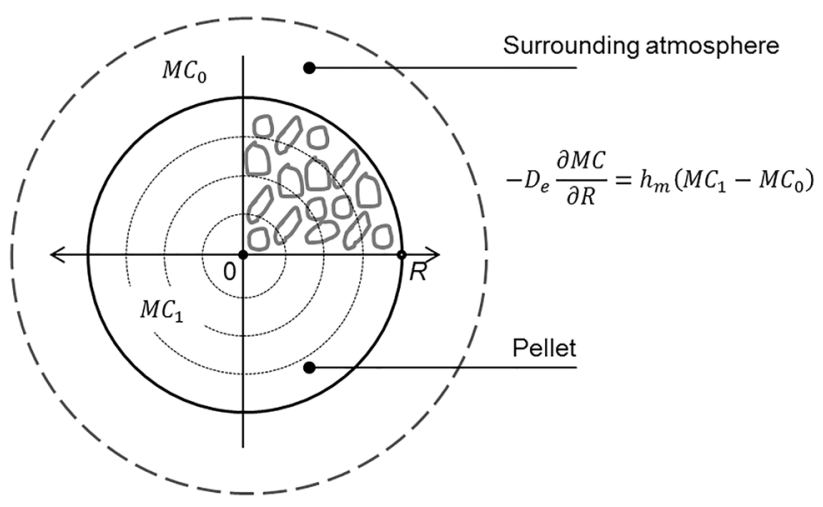

Fig. 1 One-dimensional moisture transport by evaporation from diatomaceous earth 
where $D_{e}$ is the effective diffusion coefficient (Eq. 3), which is a product of the diffusion coefficient $D_{0}$ of water in aqueous solution $\left(\mathrm{m}^{2} / \mathrm{s}\right)$ by the total porosity $\varepsilon$ of the pellet $(0 \leq \varepsilon \leq 1)$ and the tortuosity factor $\tau_{a}\left(\tau_{a} \leq 1\right)$ [29]. $\partial M C / \partial R$ is the concentration gradient of moisture in the radial direction, $h_{m}$ is the mass transfer coefficient in $\mathrm{m} / \mathrm{s}$, $M C$ is the actual moisture content of the pellet, $M C_{1}$ is the initial moisture content of the pellet, and $M C_{0}$ is the moisture content of the pellet in the equilibrium.

$D_{e}=\varepsilon D_{0} \tau_{a}$

The value of $\tau_{a}$ was calculated by using the tortuosityporosity relation for compacted bentonite $\tau_{a}=\varepsilon^{5.4}$ [29]. We considered the diffusion coefficient of the water in air $D=2.56 \times 10^{-5} \mathrm{~m}^{2} / \mathrm{s}$, and, by using an inverse method, the value $D_{0}=13.76 \times 10^{-7} \mathrm{~m}^{2} / \mathrm{s}$ was calculated. Afterwards, based on the analytical solution of Eq. (2) developed by Crank [30], the MC of the pellet at any time (i.e. in days) is given by the following equation:

$M C(t)=M C_{0}+\sum_{n=1}^{\infty} \frac{6 L^{2} \exp ^{\left(-\beta_{n}^{2} D_{e} t / R^{2}\right)}}{\beta_{n}^{2}\left\{\beta_{n}^{2}+L\left(B i_{m}-1\right)\right\}}\left(M C_{1}-M C_{0}\right)$

where $M C(t)$ is the moisture content in the pellet over the time, $t$ is the time in $s, M C_{1}$ is the initial moisture content in the pellet and $M C_{0}$ is the moisture content required to maintain the equilibrium between the surrounding atmosphere and the DE pellet, $L$ is the relation $h_{m} R / D_{e}$ where $R$ is the pellet radius in $\mathrm{m}$ and $\beta_{n}$ are roots of

$\beta_{n} \cot \beta_{n}+L-1=0$

Equation 4 requires 11 input data, which are shown in Eq. 6.

$E=\left\{t, R, C H_{1}, C H_{0}, n, \beta_{n}, L, \hat{h}_{m}, D_{e^{\prime}} \tau_{a}, \varepsilon\right\}$

\subsection{Determination of the mass transfer coefficient}

The moisture content in the surface of the pellet $M C_{s}(t)$ was calculated by using the following equation:

$\mathrm{MC}_{\mathrm{s}}(t)=\mathrm{MC}_{\mathrm{p}}(t) \cdot \rho$

where $M C_{p}(t)$ is the computed moisture content $(t \geq 0)$ in $\mathrm{kg} \mathrm{H}_{2} \mathrm{O} / \mathrm{kg}$ dry matter and $\rho$ is the density of the dry pellet calculated in $\mathrm{kg}$ dry matter $\mathrm{m}^{-3}$ dry matter. The dry matter mass is the difference between the moist mass of the pellet and the mass of the liquid phase, which was $2.0 \times 10^{-4} \mathrm{~kg}$ (equivalent to $200 \mu \mathrm{l}$ of bidistilled water). The
Raleigh number for mass transfer $\mathrm{Ra}_{\mathrm{L}}$ was estimated by Eq. 8 [31]:

$\operatorname{Ra}_{\mathrm{L}}(t)=\mathrm{Gr}_{\mathrm{L}} \mathrm{S}_{\mathrm{c}}=g \beta^{*}\left(\mathrm{MC}_{\mathrm{s}}(t)-M C_{\mathrm{a}}\right) /^{3} / v D$

where $G r_{L}$ is the Grashsof number, $g=9.81 \mathrm{~m} / \mathrm{s}^{2}$, $\beta^{*}=1 \mathrm{~m}^{3} / \mathrm{kg}, M C_{a}=20.07 \times 10^{-3} \mathrm{~kg} / \mathrm{m}^{3}$ (calculated at $23{ }^{\circ} \mathrm{C}, 96 \% \mathrm{HR}$ and $1 \mathrm{~atm}$ using the equation CIPM-2007 [32]), the characteristic length $I=1.66 \times 10^{-3}, v=1.563 \mathrm{~m}^{2} / \mathrm{s}$, the mass diffusivity $D=2.56 \times 10^{-5}$. The Sherwood number for a sphere under natural convection was calculated by the following equation [33]:

$S h(t)=2+0.589 R a_{L}^{1 / 6} /\left[1+\left(\frac{0.469}{S c}\right)^{9 / 16}\right]^{4 / 9}$

where $S_{c}=6 \times 10^{4}$. The mass transfer coefficient was calculated by:

$h_{m}(t)=S h(t) D / L$

The mean mass transfer coefficient was calculated by using the following equation.

$\hat{h}_{m}=\frac{\sum_{1}^{t} h_{m}}{t}$

For forced convection, we have:

$$
\begin{aligned}
S h_{D}= & 2+\left(0.4 R e_{D}^{1 / 2}+0.06 R e_{D}^{2 / 3}\right) S c^{0.4} \text { for } 3.5<R e_{D} \\
& <7.6 . \times 10^{4} \text { and } 0.71<S C<380
\end{aligned}
$$

where $S c$ is the Schmidt number and Re is the Reynolds number based on the diameter of the sphere.

An iterative procedure based on the analytical solution for Eq. 4 and the calculus of the roots of Eq. 5 was followed [4]. The calculation process was performed in Excel 2010 for Windows. ${ }^{\circ}, M C_{1}$ and $M C_{0}$ in Eq. 6 were experimentally determined. The value of $n$ was from 1 to 5 because five terms from the series of Eq. 5 were used in Eq. 4. $h$ and $D$ were the fitted parameters. The values of $\beta_{n}$ were taken from [30].

Equations 2 and 3 were used to calculate $D_{e}$. The mathematical model was solved in $\mathrm{COMSOL}^{\circledR} 3.4$ software, by using 10 elements in the $1 \mathrm{D}$ discretization, a time step of $20 \mathrm{~s}$, a relative tolerance of 0.01 and an absolute tolerance of 0.0010 . The UMFPACK linear system solver was used. The calculated values of $\hat{h}_{m}$ and $D_{e}$ were $3.75 \times 10^{-6} \mathrm{~m} / \mathrm{s}$ and $1.76 \times 10^{-7} \mathrm{~m}^{2} / \mathrm{s}$, respectively. The initial conditions were:

$M C_{1}=1.0 \mathrm{~kg} \cdot \mathrm{H}_{2} \mathrm{O} / \mathrm{kg}$ dry matter

and the boundary conditions were:

$M C($ surface of the pellet $)=\mathrm{dMC} / \mathrm{d} t=0$ 
$M C($ surface of the pellet $)=\frac{\mathrm{dMC}}{\mathrm{d} t}=h_{\text {convective }} \cdot\left(\mathrm{MC}_{\text {surface }}-\mathrm{MC}_{\text {surrounding }}\right)$

The root mean square error (RMSE) was calculated to determine the dispersion between calculated and experimental values:

RMSE $=\sqrt{\frac{\sum_{n=1}^{i}\left(M C_{e}-M C_{c}\right)^{2}}{m}}$

where $M C_{c}$ is the moisture content calculated with the model of natural convection or forced convection, $M C_{c}$ is the moisture content measured in the experiments and $m$ is the number of values.

\section{Results and discussion}

\subsection{Drying kinetics from DE pellets}

Figure 2 shows the mean drying kinetics of twenty $\mathrm{DE}$ pellets $(R=5 \mathrm{~mm})$. The $\mathrm{MC}_{1}$ was $\sim 1.0$ and the duration of the drying experiment was 10 days. During the trial, the $M C_{p}$ decreased to 0.25 between the fourth and fifth day, after that a slight increase $M C_{0}=0.30$ was observed at the eighth day. The $M C_{p}$ data versus time follow a quadratic equation with $R^{2}=.9570$ and the drying rate is represented by $-\mathrm{dMC}_{\mathrm{p}} / \mathrm{d} t=0.0308 t-0.2201$.

\subsection{Simulations of drying kinetics from DE pellets}

The numerical results of the model are shown in Fig. 2 . After several iterations, the minimum RMSE value between experimental data and theoretical data calculated for the

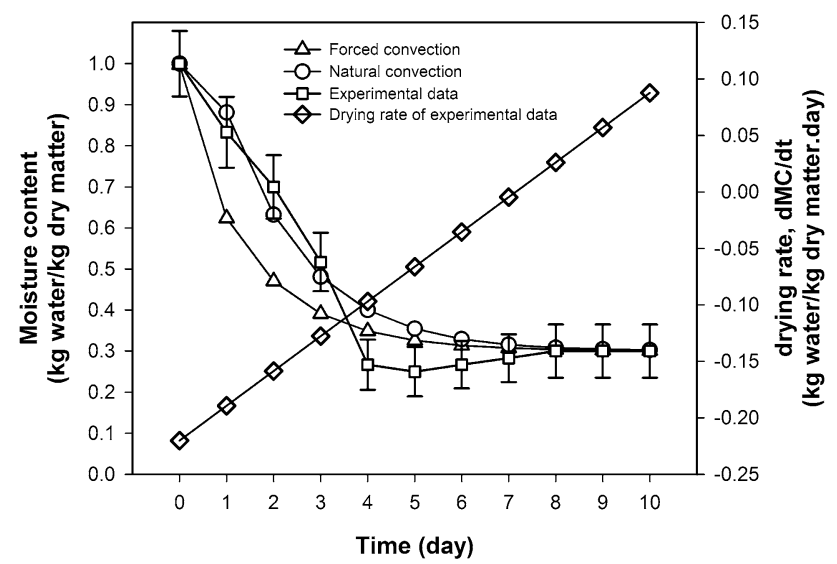

Fig. 2 Kinetics of moisture loss from diatomaceous earth pellets stored at $23{ }^{\circ} \mathrm{C}$ and $96 \% \mathrm{RH}$. Experimental data ( $\square$ ), simulations under forced convection $(\Delta)$, simulation under natural convection (O) forced convection scenario (Eq. 4) was 0.356 , the value of $\tau_{a}$ was 0.1761 , the value of $D$ was $2.747 \times 10^{-11} \mathrm{~m}^{2} / \mathrm{s}$ and $h=2.747 \times 10^{-8} \mathrm{~m} / \mathrm{s}$. The theoretical results reveals $M C_{0} \sim 0.3$ was reached until the tenth day of desiccation. For the case of natural convection scenario, the minimum RMSE value was 0.062 , the value of $D_{e}=1.76 \times 10^{-7} \mathrm{~m}^{2} / \mathrm{s}$ and $\hat{h}_{m}=3.75 \times 10^{-6} \mathrm{~m} / \mathrm{s}$. The simulation predicts an $M C_{0} \approx 0.3$ that was reached until the ninth day.

\subsection{The physics of drying kinetics}

The moisture loss of the DE pellet occurred due to the one-dimensional molecular diffusion processes into the pellet and by an evaporative process on its surface. The experimental behaviour of the moisture observed in Fig. 2 seems to represent a drying process for porous materials with a high $M C$ [34]. This theory proposes that the drying process takes place by the transition between two transport mechanisms. In the first one, the drying process happens by convection in the surface of the material and by diffusion through the boundary layer taking control of the drying rate [35], assuming that the factors involved in its development are the external conditions of mass and heat exchange in the system related to the properties of the surrounding air (temperature, environmental pressure, humidity and wind speed). The second drying period starts when the moisture content reaches the critical MC. In this period, the process transits to deeper evaporation at a rate controlled by a slower vapour diffusion inside the porous medium [35] and it is influenced by internal factors, i.e. parameters such as moisture diffusivity, water activity, the internal structure (porosity and tortuosity), and chemical composition.

During the experiments, the occurrence of radial cracks in the surface of DE pellet (Fig. 3) agree with the accelerated decrease of MC below the value of $0.25(\mathrm{w} / \mathrm{w})$, which was followed by a slow moisture uptake until $0.30(\mathrm{w} / \mathrm{w})$. A heterogeneous distribution of moisture content and the compressional and tensional internal forces caused by non-uniform shrinkage during drying, [36] are factors related to a complex change in its microstructure. They may induce softening effects that influences the internal process of moisture diffusion and affects their mechanical properties [37]. In opposite way to the presence of moisture, when it goes out of the structural inhomogeneities of the pellet, the contribution to a certain "lubricating" effect is stopped, which effects are decreased swelling of solid bridges, an augmentation of inter-particulate friction (by the hardening of sharp contacts between primary 


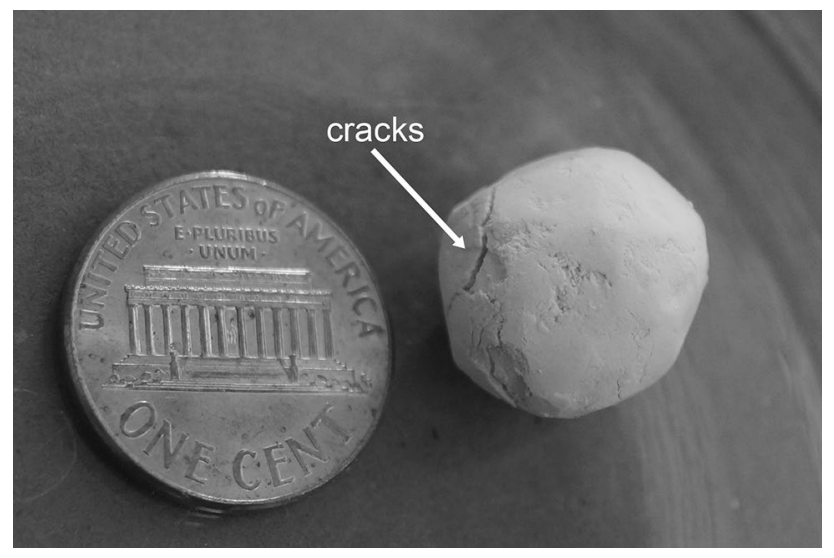

Fig. 3 Lateral view of a diatomaceous earth pellet showing cracks in the surface at the fourth day of the drying process

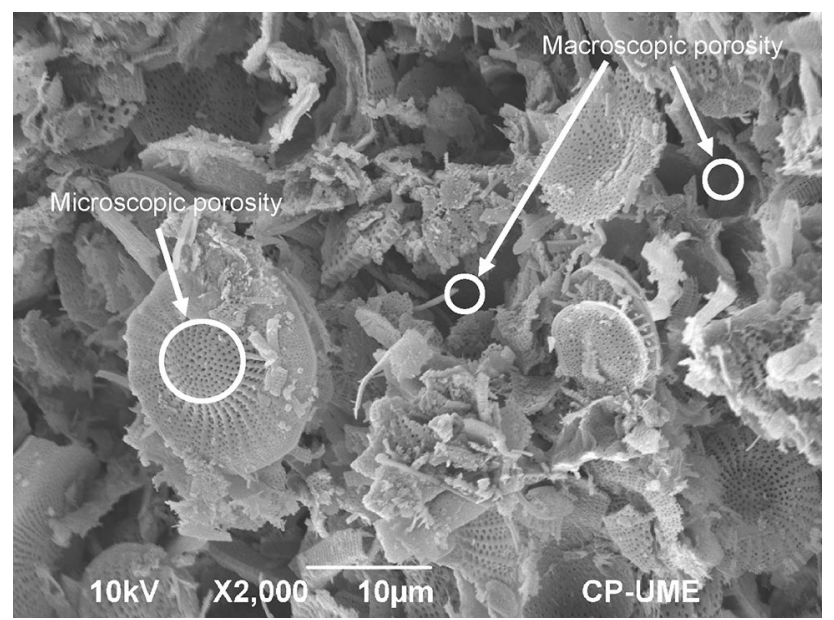

Fig. 4 Image obtained by scanning electron microscopy of internal microstructure of a mechanically elaborated diatomaceous earth pellet (Celite $209^{\mathrm{TM}}$ )

particles), there by diminish ductility and eventually complicating compliancy [40].

Porosity dominates a range of secondary properties like the air entrapment [38]. It has been proposed that the shape of the DE particles and their size distribution determine the total porosity of the DE pellet, and the repetitive compaction during rolling in the spheronization disk to form the shell of pellet has influence on the change of the relation between the solid material, channels, capillaries and pores [26]. It is well-known that a phenomenon of reabsorption of moisture is allowed by the double porosity of this kind of materials [23]. The scanning electron micrograph in Fig. 4 shows a well-distinguished double porosity in the internal section of a DE pellet. In DE pellets $(2 \mathrm{~mm}$ in diameter) was reported the total porosity as 0.725 (100\%), where the macroporosity was $0.377(52.1 \%)$, and the microporosity was 0.348 (47.9\%), particularly, small pore originates a large capillary pressure which causes more water suction than a larger pore [23]. Therefore, it can be expected that as microporosity increases and the macroporosity of the DE pellet decreases, a capillary mechanism will dominate and dissipate the effect of the diffusion mechanism [39].

Microscopic variations in structural inhomogeneities as pores, voids, hollows and solid bridge bonds also play a role in evolution of cracks during drying [40]. The repetitive compaction during the previous spheronization step can contribute to originate microcracks, then, propagation may result from an increase in the water suction of the pores inside the pellet due to a change from the solid-liquid state to the liquid-unsaturated solid-state caused by the evaporation process, where air begins to replace the water inside the pores of the pellet [41], the distances between the particles decrease and the material shrinks [36]. Immediately, cracks propagate profusely from the structural inhomogeneities during moisture uptake; as were observed in spherical zeolite granules of millimetersize [40].

Also, the effect of cracking on the $M C$ could be related to the change in the dimensions of the pores in the microstructure of large DE pellets. Since in the smaller pores the capillary meniscus can withstand longer before the air enters them [23,42], and the larger pores support less capillary pressure, water flows smoothly through the cracks and larger pores in the microstructure of the pellet. These results suggest that the DE pellet could be susceptible to cracking if the drying rate is higher. As it has been observed in kaolin clay and clays, the slower the drying process, the fewer cracks appear [36].

Another study suggests that cracking of the material under fast-drying may also depend on the evaporation properties of the liquid phase and permeability of the surface [43]; it is well-known that permeability is related to the microstructure of porous media. At particle scale, temperature also exerts an effect on capillary mechanisms because a change in temperature induces a modification of the properties of the different phases and in their interfaces [42]. The Young-Laplace equation shows that if the water-air surface tension decreases with temperature, the meniscus' radius diminishes. As a result, some pores filled with water at room temperature can drain at a higher temperature, and this decreases the saturation degree of the DE pellet [42].

\subsection{Evaporation model approach}

By assuming a porous DE pellet formed by the cohesion of particles in bulk and natural convection phenomena, the moisture transport can acceptably be analyzed by

\section{SN Applied Sciences}


the moisture evaporation model (RMSE $=0.062)$. The water effective diffusion coefficient $D_{e}$ and the mean mass transfer coefficient $\widehat{h}_{m}$ estimated had a significant influence on simulation of moisture loss from the pellet. However, considering the previously discussed factors, the model makes several simplifying assumptions that are susceptible to evaluation to explain better their effect on the accelerated MC loss observed. Hence, a model of space-time moisture transport through nonhomogeneous porous media should be tested in a future work. Compared with the moisture transfer model based on diffusion and evaporation tested by Cortes-Martínez et al. [4], the natural convection model achieved better reliability to reproduce the drying kinetics of DE pellets. In order to improve the natural convection model for practical use in the design and optimization of EPN formulations, the mortality of nematodes should be linked to the moisture evaporation from pellets through a mathematical association. Then, moisture loss rates could be optimised through material selection and storage conditions and considering the biological requirements of the EPN specie that is being formulated.

\section{Conclusions}

The moisture loss kinetics of DE pellets during storage at $23 \pm 3{ }^{\circ} \mathrm{C}$ and $96 \% \mathrm{RH}$ were identified as two-stages drying process. $M C$ migrated faster to the surrounding atmosphere during the first three days. The formation of cracks was observed and the $M C$ descends to 0.25 . A gradual increase of $M C$ reach a value of 0.3 after four days explained by the effect of capillary pressure. The drying kinetic of DE pellets can be simulated with a good prediction $(R S M E=0.0062)$ by considering a natural convection in the boundary condition in the one-dimensional transient diffusion into the porous structure. The deviation of numerical results for forced convection can be explained by a higher drying rate which allows the propagation of cracks, phenomena that was not considered in the model. The pellet cracking effect was explained by a complex change in its microstructure (double porosity) that affected the process of internal water diffusion and moisture re-absorption (capillary transport).

Acknowledgements Carlos I. Cortés-Martínez (CVU 178235) thanks Consejo Nacional de Ciencia y Tecnología (CONACyT), México for the scholarship from Estancias Posdoctorales 2do Año 2020-1/Solicitud 2020-000022-01NACV-00053. The authors thanks to Instituto Politécnico Nacional and to Dr. Heriberto Cruz-Martinez for the SEM micrographs.

\section{Compliance with ethical standards}

Conflicts of interest The authors declare that they have no conflicts of interest.

Availability of data and material Not applicable.

\section{References}

1. Grewal PS, Peters A (2005) Formulation and quality. In: Grewal PS, Ehlers RU, Shapiro-Ilan DI (eds) Nematodes as biocontrol agents. CABI, Wallingford, pp 79-90

2. Lyn ME, Burnett $D$, Garcia AR, Gray R (2010) Interaction of water with three granular biopesticide formulations. J Agric Food Chem 58(3):1804-1814. https://doi.org/10.1021/2Fjf903309s

3. Perry RN, Ehlers RU, Glazer I (2012) A realistic appraisal of methods to enhance desiccation tolerance of entomopathogenic nematodes. J Nematol 44(2):185-190

4. Cortés-Martínez $\mathrm{Cl}$, Ruiz-Vega J, Matadamas-Ortiz PT, Lewis EE, Aquino-Bolaños T, Navarro-Antonio J (2016) Effect of moisture evaporation from diatomaceous earth pellets on storage stability of Steinernema glaseri. Biocontrol Sci Technol 26(3):305-319. https://doi.org/10.1080/2F09583157.2015.1104650

5. Shapiro-llan DI, Han R, Dolinksi C (2012) Entomopathogenic nematode production and application technology. J Nematol 44(2):206-217

6. Behle R, Birthisel T (2014) Formulations of entomopathogens as bioinsecticides. In: Morales-Ramos JA, Guadalupe-Rojas M, Shapiro-llan DI (eds) Mass production of beneficial organisms: invertebrates and entomopathogens. Academic Press, Amsterdam, pp 483-517

7. Grewal PS, Bornstein-Forst S, Burnell AM, Glazer I, Jagdale GB (2006) Physiological, genetic, and molecular mechanisms of chemoreception, thermobiosis, and anhydrobiosis in entomopathogenic nematodes. Biol Control 38:54-65

8. Cruz-Martínez H, Ruiz-Vega J, Matadamas-Ortíz PT, Cortés-Martínez Cl, Rosas-Diaz J (2017) Formulation of entomopathogenic nematodes for crop pest control-a review. Plant Protect Sci 53(1):15-24

9. Lacey LA, Georgis R (2012) Entomopathogenic nematodes for control of insect pests above and below ground with comments on commercial production. J Nematol 44(2):218-225

10. Narayanasamy P (2013) Biological management of diseases of crops. Springer Science + Business Media, Dordrecht

11. Tan DT, Poh PE, Chin SK (2017) Microorganism preservation by convective air-drying - a review. Dry Technol 36(7):764-779. https://doi.org/10.1080/2F07373937.2017.1354876

12. Silver S, Dunlop D, Grove D (1995) WIPO patent no. WO 95/0577. Geneva: World Intellectual Property Organization

13. Grewal PS (2002) WIPO patent no. 2002047481. Geneva: World Intellectual Property Organization

14. Cortés-Martínez $\mathrm{Cl}$, Lewis EE, Ruiz-Vega J, Martínez-Gutiérrez GA (2017) Mechanical production of pellets for the application of entomopathogenic nematodes: effect of pre-acclimation of Steinernema glaseri on its survival time and infectivity against Phyllophaga vetula. Biocontrol Sci Technol 27(8):940-951. https ://doi.org/10.1080/2F09583157.2017.1366423

15. Robinson S (2004) Simulation: the practice of model development and use. Wiley, Chichester

16. Zhang J, Datta AK (2004) Some considerations in modeling of moisture transport in heating of hygroscopic materials. Dry Technol 22(8):1983-2008. https://doi.org/10.1081/2Fdrt-20003 2740 
17. Callahan JC, Cleary GW, Elefant M, Kaplan G, Kensler T, Nash RA (1982) Equilibrium moisture content of pharmaceutical excipients. Drug Dev Ind Pharm 8(3):355-369. https://doi. org/10.3109/2F03639048209022105

18. Tsotsas $E$ (2012) Influence of drying kinetics on particle formation: a personal perspective. Dry Technol 30:1167-1175

19. Derouane EG, Andre JM, Lucas AA (1988) Surface curvature effects in physisorption and catalysis by microporous solids and molecular sieves. J Catal 110(1):58-73. https://doi. org/10.1016/2F0021-9517/2888/2990297-7

20. Kelbaliev GI, Manafov MP (2009) Mass transfer in the process of drying of porous materials. J Eng Physic Thermophys 82(5):991-999

21. Hollewand MP, Gladden LF (1994) Probing the structure of porous pellets: an NMR study of drying. Mag Res Imag 12(2):291-294

22. Rouquerol J, Rouquerol F, Sing KS (1998) Adsorption by powders and porous solids. Academic Press, London

23. Burger CA, Shackelford CD (2001) Evaluating dual porosity of pelletized diatomaceous earth using bimodal soil-water characteristic curve functions. Canadian Geotech J 38:53-66. https ://doi.org/10.1139/t00-084

24. Welty JR, Wicks CE, Wilson RE, Rorrer GL (2008) Fundamentals of momentum, heat, and mass transfer. Wiley, New Jersey

25. Imerys (2018) Celite $209^{\mathrm{TM}}$ Technical data. https://imery s-filtration.com/north-america/wp-content/uploads/sites /10/2019/04/Celite-209-eng.pdf. Accessed 22 December 2018

26. Matadamas-Ortiz PT, Ruiz-Vega J, Vazquez-Feijoo JA, CruzMartínez H, Cortés-Martínez Cl (2014) Mechanical production of pellets for the application of entomopathogenic nematodes: factors that determine survival time of Steinernema glaseri. Biocontrol Sci Technol 24(2):145-157. https://doi. org/10.1080/2F09583157.2013.852161

27. Bear J, Cheng AHD (2010) Modeling groundwater flow and contaminant transport. Springer Science + Business Media, Berlin

28. Ljung L (1999) System identification, theory for the user. Prentice Hall, New Jersey

29. Shackelford CD, Moore SM (2013) Fickian diffusion of radionuclides for engineered containment barriers: Diffusion coefficients, porosities, and complicating issues. Eng Geol 152(1):133147. https://doi.org/10.1016/2Fj.enggeo.2012.10.014

30. Crank J (1975) The mathematics of diffusion. Clarendon Press, Oxford

31. Karwe MV, Deo I (2011) Grashof number. In: Heldman DR, Moratu $\mathrm{Cl}$ (eds) Encyclopedia of agricultural, food, and biological engineering. CRC Press, London, pp 717-719
32. Picard A, Davis RS, Gläser M, Fujii K (2008) Revised formula for the density of moist air (CIPM-2007). Metrologia 45(2):149-155. https://doi.org/10.1088/2F0026-1394/2F45/2F2/2F004

33. Sablani SS, Datta AK, Rahman MS, Mujumdar AS (2006) Handbook of food and bioprocess modeling techniques. CRC Press, Boca Raton

34. Górnicki K, Kaleta A (2011) Some problems related to mathematical modelling of mass transfer exemplified of convection drying of biological materials. In: Hossain MM (ed) Heat and mass transfer-modeling and simulation. Intech, Rijeka, pp 143-166

35. Borgman O, Fantinel P, Lühder W, Goehring L, Holtzman R (2016) Impact of spatially correlated pore-scale heterogeneity on drying porous media. Water Res 53(7):5645-5658. https://doi. org/10.1002/2016wr020260

36. Musielak G, Śliwa T (2015) Modeling and numerical simulation of clays cracking during drying. Dry Technol 33(14):1758-1767. https://doi.org/10.1080/07373937.2015.1036287

37. Russell A, Šibanc R, Dreu R, Müller P (2018) Mechanics of pharmaceutical pellets-constitutive properties, deformation, and breakage behavior. J Pharma Sci 107(2):571-586

38. Litster J, Ennis B (2004) The science and engineering of granulation processes. Springer Science + Business Media, Dordrecht

39. Laudone GM, Matthews GP, Gregory AS, Bird NRA, Whalley WR (2013) A dual-porous, inverse model of water retention to study biological and hydrological interactions in soil. Eur J Soil Sci 64(3):345-356. https://doi.org/10.1111/ejss.12055

40. Russell A, Müller P, Tomas J (2014) Quasi-static diametrical compression of characteristic elastic-plastic granules: energetic aspects at contact. Chem Eng Sci 114:70-84

41. Jones G, Zielinski M, Sentenac P (2013) Geophysical investigation of cracking in unsaturated soils. In: Caicedo B, Murillo $C$, Hoyos L, Colmenares JE, Berdugo IR (eds) Advances in unsaturated soils. CRC Press, Boca Raton, pp 203-208

42. François B, Ettahiri S (2012) Role of the soil mineralogy on the temperature dependence of the water retention curve. In: Mancuso C, Jommi C, D'Onza F (eds) Unsaturated soils: research and applications. Springer Science + Business media, Berlin, pp 173-178

43. Hu LB, Péron H, Hueckel T, Laloui L (2007) Drying shrinkage of deformable porous media: mechanisms induced by the fluid removal. In: Olson HW (ed) ASCE geotechnical special publication 157: computer applications in geotechnical engineering. American Society of Civil Engineers, Colorado, pp 1-10

Publisher's Note Springer Nature remains neutral with regard to jurisdictional claims in published maps and institutional affiliations. 